\title{
A Meta-Analysis: Correlation between Hypertension of Comorbidity on Mortality in Patients with COVID-19
}

\author{
Nanda Agustian Simatupang1), Vitri Widyaningsih"2), Sumardiyono²) \\ 1)Masters Program in Public Health, Universitas Sebelas Maret \\ 2) Faculty of Medicine, Universitas Sebelas Maret
}

\section{ABSTRACT}

Background: SARS-CoV-2 is a new type of coronavirus that has never been previously identified in humans. In severe cases of COVID-19 it can cause pneumonia, acute respiratory syndrome, kidney failure, and even death. Hypertension causes a number of pathophysiological changes in the cardiovascular system such as left ventricular hypertrophy and fibrosis. This can make a hypertensive heart particularly vulnerable to SARS-CoV-2. This study aims to analyze and estimate the effect of comorbid hypertension on mortality in COVID19 patients.

Subjects and Method: This was a systematic review and meta-analysis conducted with PRISMA flow diagram. Article searches through journal databases include: Google Scholar, PubMed, Science Direct, and Springer Link by selecting articles published in 2020 and 2021. The keywords used are "Hypertension" OR "Hypertensive Patient" OR "Blood Pressure", "Systolic Pressure" OR "Diastolic Pressure" AND "Mortality", OR "death" OR "loss" AND "COVID-19" OR "SARS-COV-2" OR "coronavirus" AND "multivariate". The inclusion criteria were full paper articles with observational research methods, the results of the analysis used the aOR value, the exposure given was comorbid hypertension, the research subjects were COVID-19 patients, with mortality outcomes. Eligible articles were analyzed using the Revman 5.3 app.

Results: A meta-analysis of 18 articles showed that confirmed COVID-19 patients who had comorbid hypertension had a 1.27 times risk of mortality compared to those without comorbid hypertension and were statistically significant $(\mathrm{aOR}=1.27 ; 95 \% \mathrm{CI}=1.14$ to $1.41 ; \mathrm{p}<0.001)$.

Conclusion: Comorbid Hypertension affects the mortality of COVID-19 patients.

Keywords: hypertension, mortality, COVID19, meta-analysis

\section{Correspondence:}

Nanda Agustian Simatupang. Masters Program in Public Health, Universitas Sebelas Maret. Jl. Ir. Sutami 36A, Surakarta 57126, Central Java. Email: nandaagustian9@gmail.com. Mobile: 082247604322.

\section{Cite this as:}

Simatupang NA, Widyaningsih V, Sumardiyono (2021). Meta-Analysis: The Effectiveness of Zincon Dhiarrea and Pneumonia in Children Under Five. J Epidemiol Public Health. 06(01): 60-69. https://doi.org/10.26911/jepublichealth.2021.06.01.07.

cc) (i) (2) Journal of Epidemiology and Public Healthis licensed under a Creative Commons cc) Attribution-NonCommercial-ShareAlike 4.0 International License.

\section{BACKGROUND}

Coronavirus Disease 2019 (COVID-19) is an infectious disease caused by Severe Acute Respiratory Syndrome Coronavirus 2 (SARS-CoV-2). SARS-CoV-2 is a new type of coronavirus that has never been previously identified in humans. There are at least two types of coronavirus that are known to cause diseases that can cause severe symptoms such as Middle East Respiratory Syndrome (MERS) and Severe Acute Respiratory Syndrome (SARS). Common signs and symptoms of COVID-19 infection include symptoms of acute respiratory distress such as fever, cough and shortness of breath. The average incubation period is 5-6 days with the longest incubation period being 14 days. In severe cases 
of COVID-19 it can cause pneumonia, acute respiratory syndrome, kidney failure, and even death (WHO, 2020a).

At the end of December 2019, pneumonia occurred in Wuhan City, Hubei Province, China whose etiology was unknown, after identification of the case, including a new type of corona virus. On January 30, 2020 WHO declared the incident a Public Health Emergency of International Concern (PHEIC) and on March 11, 2020, WHO had declared COVID-19 a pandemic (WHO, 2020b).

The increase in the number of cases took place quite quickly, and spread to various countries around the world in a short time. As of March 31, 2021, WHO reported 127,928,144 confirmed cases with 2,797,295 deaths worldwide. The COVID-19 Case Fatality Rate (CFR) is 2.2\%. From these global data, the Americas became the highest contributor to 56 million cases, while the European region (44.8 million cases) and Southeast Asia (15.1 million cases) became the second and third highest contributor areas (WHO, 202Oc).

Emerging data from the countries most affected by the coronavirus disease 2019 (COVID-19) reveal that hypertension is strongly associated with poor clinical outcomes. Hypertension causes a number of pathophysiological changes in the cardiovascular system such as left ventricular hypertrophy and fibrosis. This can make a hypertensive heart very vulnerable to SARS-CoV-2 (Kulkarni, 2020).

Hypertension which is a non-communicable disease (NCD) is one of the main causes of death and disability worldwide. Non-communicable diseases cause $71 \%$ of global deaths and claim the lives of 57 million people each year. Data from the World Health Organization (WHO) in 2015 showed that around 1.13 billion people in the world have hypertension, meaning that
1 in 3 people in the world is diagnosed with hypertension. The number of people with hypertension continues to increase every year, it is estimated that by 2025 there will be 1.5 billion people affected by hypertension, and it is estimated that every year 10.44 million people die from hypertension and its complications (WHO, 2015).

Most people who have hypertension do not know that they have hypertension because of the lack of public attention to always control blood pressure. Hypertension also rarely shows symptoms, and its recognition is usually through screening, or when seeking medical attention for unrelated health problems (Bell K, 2015).

Based on the background above and several research findings on the severity and mortality of COVID-19 patients caused by comorbid hypertension, the researchers are interested in conducting a study using a systematic review and meta-analysis that can summarize some of the results of primary studies or previous research with a systematic search to combine the results and get more precise estimates to draw new conclusions.

\section{SUBJECTS AND METHOD}

\section{Study Design}

The study design used in this research is a systematic review and meta-analysis, using PRISMA flow diagram guidelines. Article searches were carried out using a journal database which included: Google Scholar, PubMed, Science Direct, and Springer Link by selecting articles published in 2020 April 2021. The keywords used were "Hypertension" OR "Hypertensive Patient" OR "Blood Pressure ", "Systolic Pressure" OR "Diastolic Pressure" AND "Mortality", OR "death" OR "loss" AND "COVID-19" OR "SARS-COV-2" OR “coronavirus" AND "multivariate". 


\section{Inclusion Criteria}

The inclusion criteria were full paper articles with observational research methods, the results of the analysis used the aOR value, the exposure given was comorbid hypertension, the research subjects were COVID-19 patients, with mortality outcomes.

\section{Exclusion Criteria}

Exclusion criteria in this study include articles published other than English.

\section{Operational Definition of Variable}

In formulating the problem in this study, the author uses PICO. Population is confirmed COVID-19. Intervention is having hypertension comorbidity, with comparison that is having hypertension comorbidity and outcome is patient mortality.

Hypertension is an abnormal increase in blood pressure in the arteries with a systolic blood pressure of more than $140 \mathrm{mmHg}$, and/or diastolic blood pressure $\geq 90 \mathrm{mmHg}$ on two measurements with an interval of 5 minutes in a state of sufficient rest (quiet). Determination of hypertension can be in the form of medical records, direct measurements, or self-reports.

Someone is declared confirmed COVID-19 or infected with the acute SARSCoV-2 virus based on the detection of a unique viral sequence through the Nucleic Acid Amplification Test (NAAT), such as real time reverse-transcription polymerase chain reaction (rRT-PCR) (WHO, 2020d).

\section{Instruments}

A sphygmomanometer or medical record data is used as a measuring tool for hypertension, in COVID-19 patients using the Nucleic Acid Amplification Test (NAAT) or Antigen Rapid Diagnostic Test (RDT).

\section{Data Analysis}

Data analysis in this study used the Review Manager application (RevMan 5.3). Data were analyzed based on variations between studies by determining the use of random effects analysis models. This study used I2 to quantify the dispersion. The results of data analysis are in the form of the effect size value of the heterogeneity of the study which later the results of the analyzed data are interpreted in the form of forest plots and funnel plots.

\section{RESULTS}

Research from the primary study related to the effect of comorbid hypertension on mortality in COVID-19 patients consisted of 18 articles from 4 continents, namely Asia, Europe, North America, and South America. There are 5 studies from the Asian continent (2 Indonesia, 1 China, and 1 Kuwait, and 1 Saudi Arabia), 5 studies from the European continent (2 Spain, 1 Italy, 1 England, and 1 Sweden), 7 studies from the North American continent (4 USA, 2 Mexico, 1 Chicago), and 1 study from the South American continent (Bolivia).

The article search was carried out using a database based on the PRISMA flow diagram, which can be seen in Figure 1. The study quality assessment was carried out qualitatively and quantitatively. Quality assessment in this study uses the Critical Appraisal for Cohort Study (CEBMa, 2014). The answer (Yes) will be given a score of 1 and the answer (No) will be given a score of o. On the confounding number question points, if there is only one of the 2 confounding factors (age and gender), it will be given a score of $\mathrm{o}$. After the study quality assessment is carried out, a total of 18 articles included in the meta-analysis quantitative synthesis process were analyzed using RevMan 5.3. 


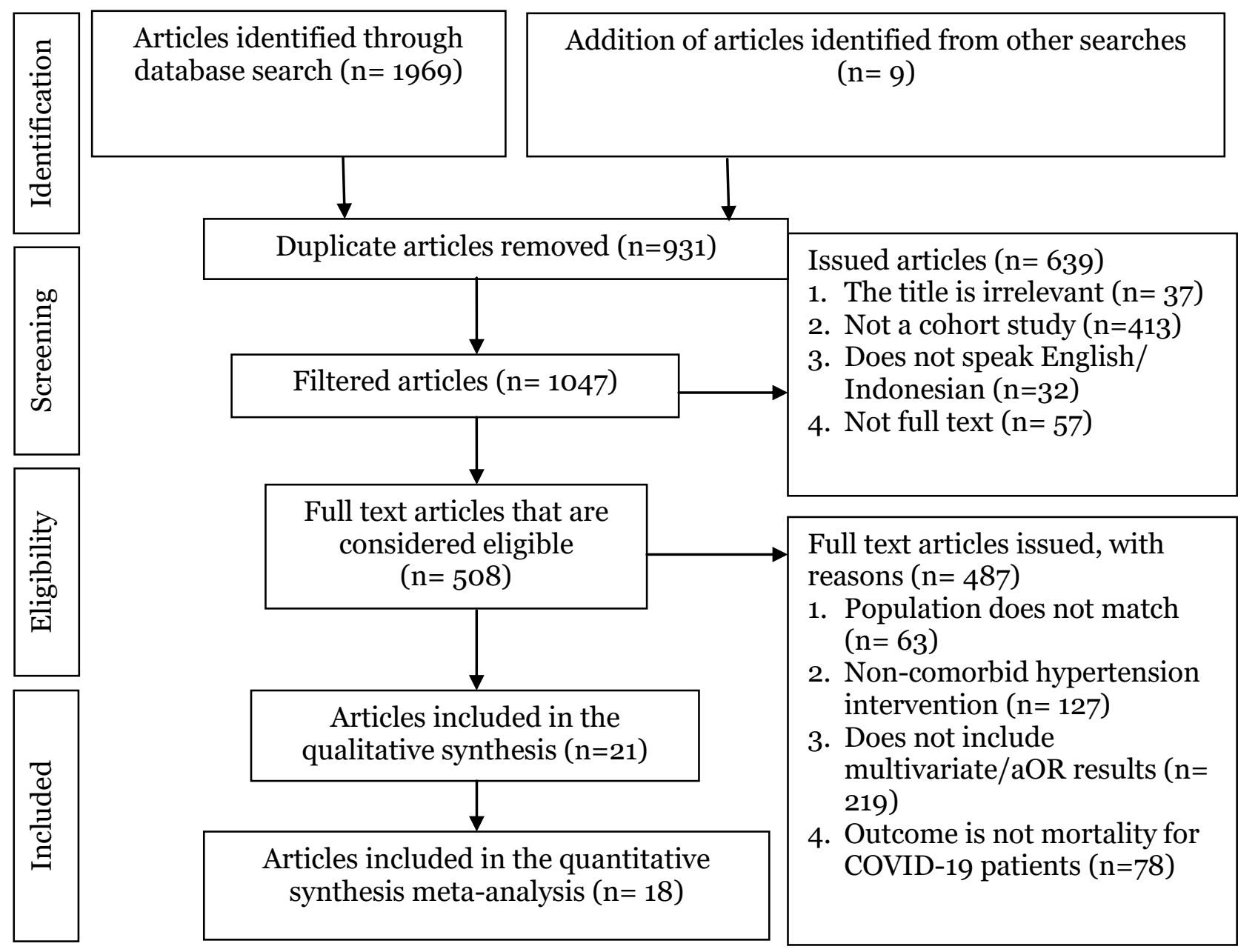

Figure 1. PRISMA flow diagram

\section{Forest plot}

Interpretation of the results of the metaanalysis process can be seen through the forest plot. Figure 4 shows that COVID-19 patients who had comorbid hypertension were 1.27 times more likely to die (mortality) compared to those without comorbid hypertension and were statistically signifycant $(\mathrm{aOR}=1.27 ; 95 \% \mathrm{CI}=1.14$ to 1.41 ; $\mathrm{p}<0.001)$. The heterogeneity of the research data shows $\mathrm{I}^{2}=70 \%$, so that the distribution of the data is said to be heterogeneous, thus the Random Effect Model is used in the data analysis in this forest plot.

\section{Funnel Plot}

A funnel plot is a plot that depicts the estimated effect size of each study against an estimate of its accuracy which is usually the standard error. Based on Figure 4.5, it shows that there is no publication bias which is indicated by the symmetrical distribution of the right and left plots where there are 8 plots on the left and 10 plots on the right. The plot on the left of the graph appears to have a standard error of between 0.02 and 0.56 and the plot on the right has a standard error of 0.13 to 0.50 . 
Simatupang et al./ Hypertension of Comorbidity on Mortality in Patients with COVID-19

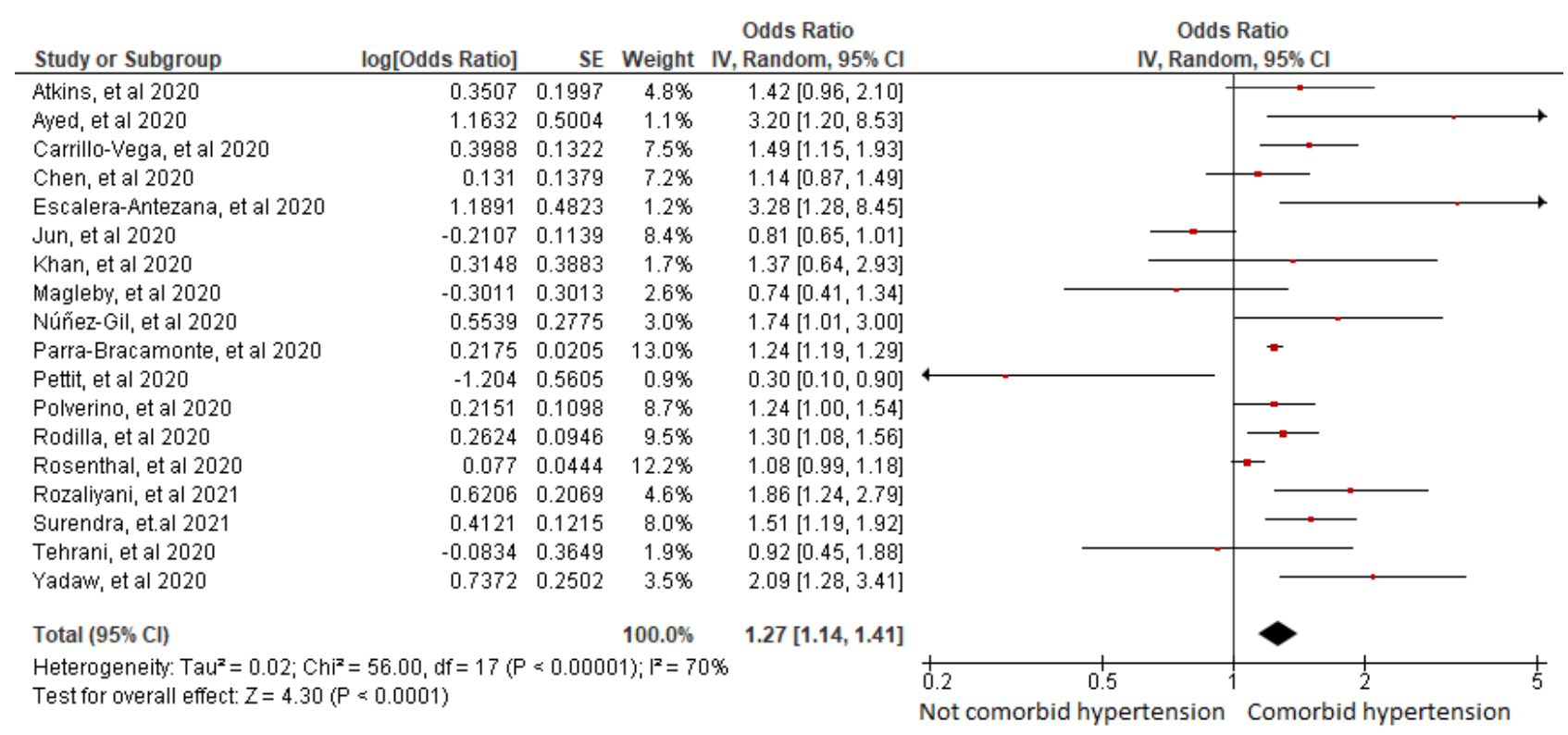

Figure 2. Forest Plot Effect of Comorbid Hypertension on the Mortality of COVID-19 Patients

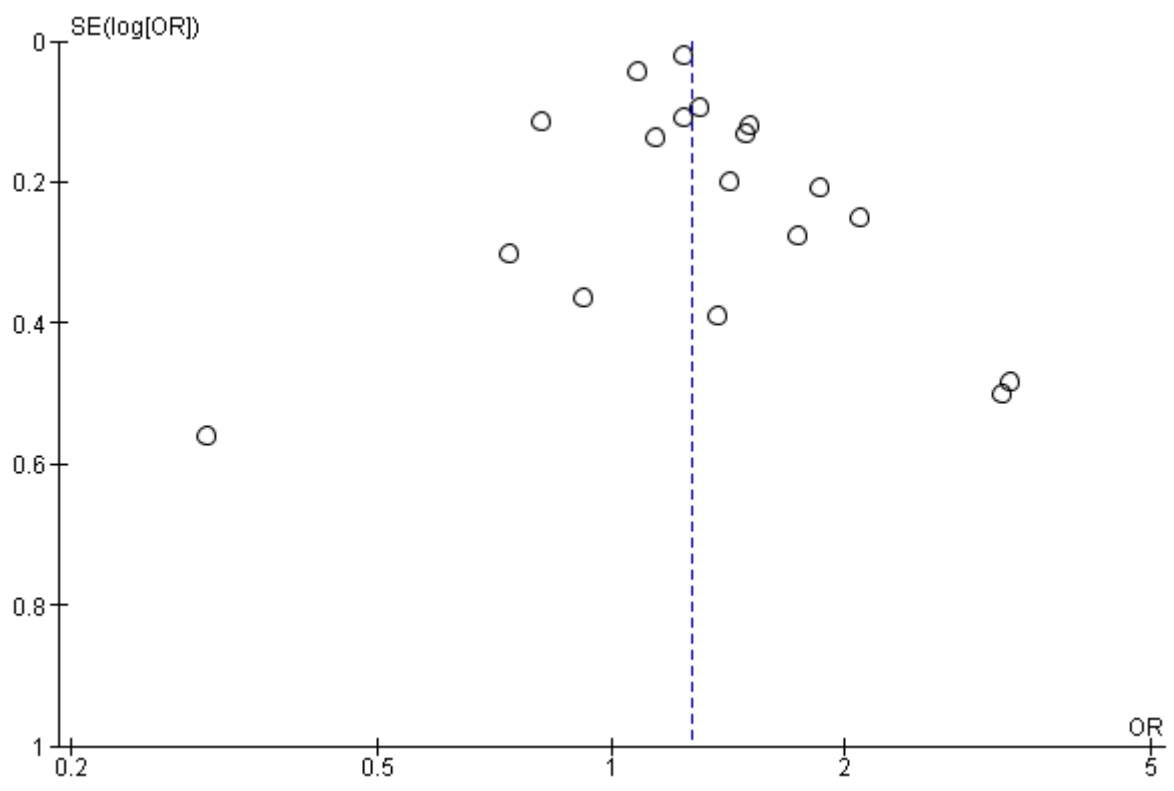

\section{Figure 3. Funnel Plot Effect of Comorbid Hypertension on the Mortality of COVID-19 Patients}

\section{DISCUSSION}

There are 18 observational research articles with cohort studies as a source of metaanalysis of the effect of comorbid hypertension on mortality in COVID-19 patients. The results of the forest plot of articles showed that patients with confirmed COVID-19 who had comorbid hypertension had 1.27 times risk of mortality compared to those who did not/do not have comorbid hypertension and the results were statistically significant $(\mathrm{aOR}=1.27 ; 95 \% \mathrm{CI}=1.14$ to $1.41 ; \mathrm{p}<0.001)$.

The results of this study are supported by a study conducted by Albitar (2020), that confirmed COVID 19 patients with 
comorbid hypertension will have a 3.5 times risk of experiencing mortality $(\mathrm{aOR}=$ $3.57 ; 95 \% \mathrm{CI}=1.69$ to $7.54 ; \mathrm{p}=0.001$ ). Gender was also an influencing factor, higher mortality was associated with higher rates of chronic comorbidities among men, hypertension, and other comorbidities (cardiovascular and pulmonary), and higher rates of smoking.

Another study conducted by Moon (2020), stated that patients with confirmed COVID 19 with comorbid hypertension had almost 2 times the risk of experiencing mortality (OR=1.95; 95\% CI $=0.70$ to 5.42$)$. Hypertension comorbid became the most common comorbid among those who died with $58.3 \%$ having hypertension. The elderly in care facilities or inpatients with comorbid diseases should receive more attention and be considered for preventive quarantine karantina.

A similar study on the effect of comorbid hypertension factors on the mortality of patients with confirmed COVID-19 was conducted by Sulistyowati (2021), who stated that patients with confirmed COVID19 with comorbid hypertension had a 2.44 times risk of mortality compared to those without comorbid/ non-hypertensive comorbid and statistically significant (OR= 2.43; 95\% CI=1.00 to $5.88 ; \mathrm{p}=0.043$ ).

Hypertension comorbidity is the most common comorbid compared to other comorbidities in confirmed COVID-19 patients. So this needs special attention because comorbid hypertension is also a risk factor for other diseases such as cardiovascular, stroke, and kidney failure. Likewise with Sitorus (2021), the results showed that COVID-19 patients who died in hospital had symptoms of dyspnea and had a history of contact with confirmed COVID19 positive patients. Patients who have comorbidities have a greater risk of death than patients who do not have comorbidities.

Windiyaningsih (2021), in his study stated that the comorbid hypertension was the most common comorbid in the death of patients with confirmed COVID-19 at 35\% compared to other comorbidities. Comorbid hypertension is also a risk factor for death of COVID-19 patients by 2.67 times compared to other comorbidities (OR= 2.67; 95\% CI= 1.04-0.85; $\mathrm{p}=0.038)$. Patients with hypertension tend to have an increased inflammatory index, tissue hypoxia, and cellular immune injury. (C-Reactive Protein) CRP and blood sedimentation rates increase and the differentiation group of $\mathrm{CD} 4+$ and $\mathrm{CD} 8+$ cells will decrease significantly in patients with hypertension, Ciardullo (2020), in his study stated that the most common comorbid conditions in patients with confirmed COVID-19 is hypertension as much as $64.8 \%$. And can increase the risk of death in patients with confirmed COVID-19.

This study is not in line with Palaiodimos (2020) which found that comorbid hypertension was not a risk factor for death in confirmed patient mortality at a New York hospital, US but was not statistically significant $(\mathrm{OR}=0.93$; 95\% CI= 0.44 -1.98; $\mathrm{p}=0.853$ ). Another study conducted by Jun (2020) also stated that hypertension was not a mortality factor for COVID-19 patients $(\mathrm{aOR}=0.81 ; 95 \% \mathrm{CI}=0.648$ to 1.00 ; $\mathrm{p}=0.051)$.

In one of the primary studies, namely by Pettit (2020), showed that aOR in comorbid hypertension reduced 0.3 times mortality in patients with confirmed COVID-19. These results do not support the theory that comorbid hypertension will increase the risk of mortality in patients with confirmed COVID-19. A similar study was also conducted by Magleby (2020) in New York, USA. The results showed that 
comorbid hypertension could reduce mortality in patients with confirmed COVID-19 by 0.74 times, but it has not been proven to be statistically significant (aOR $=0.74 ; 95 \%$ $\mathrm{CI}=0.41$ to $-1.33 ; \mathrm{p}=0.310$ ).

In a systematic review by Willim (2020), stated that patients with comorbid hypertension have a higher risk of experiencing more severe manifestations if infected with COVID-19 because it is thought to be associated with increased ACE2 expression in this group compared to patients without comorbid hypertension. Hypertension in COVID-19 patients can also trigger cardiovascular complications such as acute heart failure, myocardial injury, myocarditis, acute myocardial infarction, thromboembolism, and arrhythmias.

ACE is an enzyme that plays a role in catalyzing the conversion of angiotensin I to angiotensin II which plays a role in vasoconstriction and increasing blood pressure. ACE2 functions as a functional coronavirus receptor that can bind to the viral surface spike protein directly. SARS-CoV-2 enters host cells via the ACE2 receptor which is abundant in the lungs (especially in type II alveolar cells). ACE2 is also abundant in the heart. In addition, ACE2 is also found in intestinal epithelium, vascular endothelium, and kidney; this is the basis for the mechanism of multiorgan dysfunction that can occur in SARS-CoV-2 infection (Clerkin, 2020).

Patients with comorbid hypertension are more susceptible to infection with SARS-CoV-2 and may experience more severe clinical manifestations thought to be associated with increased ACE2 expression in this group than patients without comorbid hypertension (Chen, 2020).

Another study conducted by Costa suggested that patients with cardiovascular comorbidities such as hypertension and coronary heart disease (CHD) are more at risk for more severe manifestations if infected with SARS-CoV-2 and contribute to the majority of deaths in COVID-19. This is thought to be due to higher ACE2 expression in patients with cardiovascular disease (Costa, 2020). Continuously high blood pressure causes damage to the arterial system slowly. These arteries harden caused by fatty deposits on the walls, thereby narrowing the lumen contained in the blood vessels causing CHD. Increased systemic blood pressure due to hypertension increases resistance to pumping blood from the left ventricle, so that the workload of the heart increases (Marliani, 2013). This will further worsen the situation for patients with confirmed COVID-19.

Coronavirus infection attacks the respiratory tract, namely the lungs and then damages the heart, so someone who has cardiovascular disease and hypertension is more at risk of infection and death. Corona virus infection appears to be more severe than other viruses because it causes damage to the heart muscle which is detected by measuring the Troponin protein in the blood and can cause heart injuries such as pericarditis (inflammation of the lining of the heart) and myocarditis (inflammation of the heart muscle) (Ilpaj, 2020).

\section{FUNDING AND SPONSORSHIP}

This study is self-funded.

\section{AUTHOR CONTRIBUTION}

Nanda Agustian Simatupang is the main researcher who selects the topic, searches and collects research data. Vitri Widyaningsih and Sumardiyono analyzed data and reviewed research documents.

CONFLICT OF INTEREST

There is no conflict of interest in this study. 


\section{ACKNOWLEDGEMENT}

The researcher would like to thank the database providers PubMed, Science Direct, Google Scholar and Springer Link.

\section{REFERENCES}

Albitar O, Ballouze R, Ooi JP, Ghadzi S (2020). Risk factors for mortality among COVID-19 patients. Diabetes research and clinical practice, 166. 108293.https://doi.org/10.1016/j.dia bres.2020.108293.

Atkins JL, Masoli JAH, Delgado J, Pilling LC, Kuo CL, Kuchel GA, Melzer D (2020) Preexisting Comorbidities Predicting COVID-19 and Mortality in the UK Biobank Community Cohort, The journals of gerontology. Series A, Biological sciences and medical sciences, 75(11): 2224-2230. doi: 10.1093/gerona/glaa183.

Ayed M, Borahmah AA, Yazdani A, Sultan A, Mossad A, Rawdhan H (2021). Assessment of Clinical Characteristics and Mortality-Associated Factors in COVID-19 Critical Cases in Kuwait. Med Princ Pract, 30(2):185-192. doi: 10.1159/000513047.

Bell K, Twiggs J, Olin BR (2015). Hypertension: the silent Killer: updated JNC8 guideline recommendations associate clinical professor of pharmacy practice drug information and learning resource center. Alabama Pharmacy Association:1-8. https://cdn.ymaws.com/www.aparx.org/reso urce/resmgr/CEs-/CE_Hypertension_The_Silent_K.pdf

Carrillo-Vega MF, Salinas-Escudero G, García-Peña C, Gutiérrez-Robledo L M, Parra-Rodríguez L (2020). Early estimation of the risk factors for hospitalization and mortality by COVID19 in Mexico. PloS one, 15(9). e0238905.https://doi.org/10.1371- /journal.pone.0238905.

CEBMa (2014). Critical Appraisal for crosssectional study. Amsterdam: Center for Evidence Based Management. https://cebma.org/wp-content/uploads/Critical-Appraisal-Questionsfor-a-Cross-Sectional-Study-July2014-1.pdf.

Chen H, Yan W, Yang D, Chen G, Ma K, Xu $\mathrm{D}, \mathrm{Yu} \mathrm{H}$, et al (2020). Clinical characteristics of 113 deceased patients with coronavirus disease 2019: retrospective study. BMJ, 368(3): 1-14. doi: 10.1136/bmj.m1295.

Ciardullo S, Zerbini F, Perra S, Muraca E, Cannistraci R, Lauriola M, Grosso P, Lattuada $G$ (2021). Impact of diabetes on COVID-19-related in-hospital mortality: a retrospective study from Northern Italy. J Endocrinol Invest, 44(4): 843-850. doi: 10.1007/s40618020-01382-7.

Clerkin KJ, Fried JA, Raikhelkar J (2020). COVID-19 and cardiovascular disease. Circulation, 141(6): 1648-1655. doi:10.1161/CIRCULATIONAHA.120.046941.

Costa R, Castagna A, Ruotolo G (2020). COVID-19 and cardiovascular problems in elderly patients: Food for thought. Aging Medicine, 1-7. https://doi.org/10.1002/agm2.12149.

Escalera-Antezana JP, Lizon-Ferrufino NF, Maldonado-Alanoca A, Alarcon-Dela-Vega G, Alvarado-Arnez LE, Balderrama-Saavedra MA, Bonilla-Aldana DK, Rodriguez-Morales AJ (2020). Risk factors for mortality in patients with Coronavirus Disease 2019 (COVID-19) in Bolivia: An analysis of the first 107 confirmed cases. Infez Med, 28(2): 238-242. PMID: 32487789.

Ilpaj SM, Nurwati N (2020). Analisis Pengaruh Tingkat Kematian Akibat 
Covid-19 (Analysis of the Effect of Death Rates Due to Covid-19). Jurnal Pekerjaan Sosial, 3(1): 16-28. http://jurnal.unpad.ac.id/focus/article/view/28123

Jun T, Nirenberg S, Kovatch P, Huang $\mathrm{K}$ (2020). Sex-specificity of mortality risk factors among hospitalized COVID-19 patients in New York City: prospective cohort study. medRxiv, 29(1): 1-12. https://doi.org/10.1101/2020.07.29.20164640.

Khan A, Althunayyan S, Alsofayan Y, Alotaibi R, Mubarak A, Arafat M, Assiri A, Jokhdar H (2020). Risk factors associated with worse outcomes in COVID-19: a retrospective study in Saudi Arabia. East Mediterr Health J, 26(11): 1371-1380. doi: 10.26719/emhj.20.130.

Kulkarni S, Jenner BL, Wilkinson I (2020). COVID-19 and hypertension. JRAAS, 21(2). doi: 10.1177/1470320320927851.

Magleby R, Westblade LF, Trzebucki A, Simon MS, Rajan M, Park J, Satlin MJ (2020). Impact of SARS-CoV-2 viral load on risk of intubation and mortality among hospitalized patients with coronavirus disease 2019. Clin Infect Dis. 1-19. https://dx.doi.org/$10.1093 \% 2 F c i d \% 2 F c i a a 851$.

Marliani (2013). Hipertensi. Jakarta: PT. Gramedia.

Moon SS, Lee K, Park J, Yun S, Lee YS, Lee DS (2020). Clinical characteristics and mortality predictors of COVID-19 patients hospitalized at nationallydesignated treatment hospitals. Journal of Korean medical science, 35(36): 328. https://doi.org/10.3346/jkms.2020.35.e328

Núñez-Gil IJ, Fernández-Pérez C, Estrada V, Becerra-Muñoz VM, El-Battrawy I, Uribarri A, Fernández-Rozas I, et al.
(2020). Mortality risk assessment in Spain and Italy, insights of the HOPE COVID-19 registry. Intern Emerg Med, 9: 1-10. doi: 10.1007/s11739020-02543-5.

Palaiodimos L, Kokkinidis DG, Li W, Karamanis D, Ognibene J, Arora S, Southern WN, et al. (2021). Severe obesity is associated with higher inhospital mortality in a cohort of patients with COVID-19 in the Bronx, New York. Metabolism: Clinical and Experimental, 108: 1-10. DOI: 10.1016/j.metabol.2020.154262.

Parra-Bracamonte GM, Lopez-Villalobos N, Parra-Bracamonte FE (2020). Clinical characteristics and risk factors for mortality of patients with COVID-19 in a large data set from Mexico. Ann Epidemiol, 52: 93-98. doi: 10.1016/j.annepidem.2020.08.005.

Pettit NN, MacKenzie EL, Ridgway J, Pursell K, Ash D, Patel B, Pho MT (2020). Obesity is associated with increased risk for mortality among hospitalized patients with COVID-19. Obesity, 28(10): 1806-1810. doi:10.1002/oby.22941.

Polverino F, Stern DA, Ruocco G, Balestro E, Bassetti M, Candelli M, Cirillo B, Contoli M, et al. (2020). Comorbidities, cardiovascular therapies, and COVID-19 mortality: A Nationwide, Italian observational study (ItaliCO). Front Cardiovasc Med, 7: 566-585. doi: 10.3389/fcvm.2020.585866.

Rodilla E, Saura A, Jiménez I, Mendizábal A, Pineda-Cantero A, Lorenzo-Hernández E, Fidalgo-Montero MDP, et al. (2020). Association of Hypertension with All-Cause Mortality among Hospitalized Patients with COVID-19. J Clin Med, 9(10): 31-36. doi: 10.3390/jcm9103136.

Rosenthal N, Cao Z, Gundrum J, Sianis J, 
Safo S (2020). Risk Factors Associated With In-Hospital Mortality in a US National Sample of Patients With COVID-19. JAMA Netw Open, 3(12): 20-29. doi: 10.1001/jamanetworkopen.2020.29058.

Rozaliyani A, Savitri AI, Setianingrum F, Shelly TN, Ratnasari V, Kuswindarti R, Salama N, Oktavia D, Widyastuti W, Handayani D (2020). Factors associated with death in COVID-19 patients in Jakarta, Indonesia: An. Acta Med epidemiological study Indones, 52(3): 246-254.

Sitorus RJ, Antara YN, Elviani R, Ahmad Z, Hudari H, Sangalang RV (2021)Risk Factor for Mortality in COVID-19 Patients in Mohammad Hoesin Hospital, Palembang, Indonesia. Jurnal Ilmu Kesehatan Masyarakat, 12(1): 69-76. https://doi.org/10.26553/jikm.2021.12.1.69-76.

Sulistyowati ES, Muningga SD, Silalahi V (2021). Risk factors of Covid-19 confirmed died patients in $\mathrm{Dr}$. Kariadi hospital: A Retrospective Study. IJTID, 9(1): 1-8. https://e-journal.unair.ac.id/IJTID/article/download/ 22609/14008

Surendra H, Elyazar IR, Djaafara BA, Ekawati LL, Saraswati K, Adrian V, Widyastuti, Oktavia D, Salama N, et al (2021). Clinical characteristics and mortality associated with COVID-19 in Jakarta, Indonesia: A hospitalbased retrospective cohort study. Lancet Reg Health West Pac, 100-108. doi: 10.1016/j.lanwpc.2021.100108.

Tehrani S, Killander A, Åstrand P, Jakobsson J, Gille-Johnson P(2021). Risk factors for death in adult COVID-19 patients: Frailty predicts fatal outcome in older patients. Int J Infect Di, 102: 415-421. doi: 10.1016/j.ijid.2020.10.071.
WHO (2015). Hypertension. World Health Organization. https://www.who.int/news-room/fact-sheets/detail/hypertension.

WHO (2020a). Coronavirus. World Health Organization. https://www.who.int/health-topics/coronavirus.

WHO (2020b). WHO Coronavirus Disease (COVID-19). https://covid19.who.int/.

WHO (2020c). Coronavirus disease 2019 (COVID-19) Situation Report - 82. Https://www.who.int/docs/defaultsource/coronaviruse/situation-reports/20200411-sitrep-82-covid-19.pdf?sfvrsn=74a5d15_2.

WHO (2020d). Laboratory testing for 2019 novel coronavirus (2019-nCoV) in suspected human cases. https://www.who.int/publications-detail/laboratory-testing-for-2019-novelcoronavirus-in-suspected-humancases.

Willim HA, Ketaren I, Supit AI (2020). Dampak Coronavirus Disease 2019 terhadap Sistem Kardiovaskular. eClinic. (2): 237-245. 10.35790/ecl.8.2.2020.30540.

Windiyaningsih C, Hayatunnisa NU, Sulistowati Y, Nurhastuti T, Yanuar IES, Rahardjo TBW (2021). Etiology COVID-19 mortality in Jakarta hospital in the first COVID-19 outbreak in Indonesia. Current Pediatric Research, 25 (3): 393-397. https://scholar.ui.ac.id/en/publications/etiologycovid-19-mortality-in-jakarta-hospital-in-the-first-covid.

Yadaw AS, Li YC, Bose S, Iyengar R, Bunyavanich S, Pandey G (2020). Clinical features of COVID-19 mortality: development and validation of a clinical prediction model. Lancet Digit Health, 10: 516-525. doi: 10.1016/S2589-7500(20)30217-X. 